\title{
Aplicação e análise da ferramenta 'índice comportamental' na gestão de uma obra conceptual de Joseph Kosuth
}

\author{
Francisca Sousa
}

Resumo: Este artigo documenta a aplicação da ferramenta de gestão de arte conceptual 'índice comportamental' (Stigter 2011) a One and three plants, 1965 de Joseph Kosuth. A arte contemporânea engloba diversas obras com características variáveis, frequentemente intrínsecas. A análise do 'comportamento' de determinada obra ao longo do tempo e das suas iterações, permite-nos construir uma perspetiva biográfica que pode auxiliar um processo de decisão mais consciente e responsável. Dado o vasto espectro de documentação gerada na instalação e conservação destas obras, urge apelar a uma abordagem de conservação que seja sistemática, simplificada e de fácil interpretação. $O$ 'índice comportamental' permite abranger grandes quantidades de informação, frequentemente subjetiva, num sumário biográfico com uma importante componente visual e esquemática. A aplicação desta ferramenta a One and three plants permitiu delimitar o espectro da sua variabilidade, refletindo sobre apresentações passadas e eventuais exposições futuras numa apreciação crítica essencial para a sua preservação.

Palavras-chave: conservação de arte contemporânea, obras variáveis, índice comportamental, Joseph Kosuth, arte conceptual

\section{Aplicación y analysis de la herramienta 'índice comportamental' en la gestión de una obra de arte conceptual de Joseph Kosuth}

Resumen: Este texto documenta la utilización de la herramienta de gestión del arte conceptual 'índice comportamental'(Stigter 2011) a la gestión de One and three plants, 1965 de Joseph Kosuth. El arte contemporáneo incluye obras con características variables, a menudo intrínsecas. El análisis del 'comportamiento' de una obra a lo largo del tiempo y sus iteraciones, nos permite recoger una perspectiva biográfica que puede ayudar una toma de decisiones más consciente y responsable. Dado el amplio espectro de documentación generada en la instalación y conservación de estas obras, urge apelar a un enfoque de conservación sistemático, simplificado y de fácil interpretación. El 'índice comportamental' permite cubrir grandes cantidades de información, a menudo subjetiva, en un resumen biográfico con un importante componente visual y esquemático. Su aplicación a One and three plants permitió delimitar el espectro de variabilidad, reflexionando sobre presentaciones pasadas y eventuales exposiciones futuras en una valoración crítica imprescindible para su preservación.

Palabras clave: conservación del arte contemporáneo, obras variables, índice comportamental, Joseph Kosuth, arte conceptual

\begin{abstract}
Using and analyzing the 'behavior index' tool to manage a conceptual artwork by Joseph Kosuth
Abstract: This article intends to apply a conceptual tool denominated 'behavior index' (Stigter 2011) to manage the artwork One and three plants, 1965 by Joseph Kosuth. Analyzing a variable artwork's 'behavior' through time and its different iterations, allows us to have a biographical perspective on it and enables a more accountable decision-making process for its preservation. Given the broad spectra of documentation created and archived whenever artworks with variable characteristics are installed, a systematic, simple and easily interpreted approach is needed. This tool enables institutions to encompass great amounts of information, often subjective, into a visible summary of the artwork's biography. Applying this tool to One and three plants has allowed the definition of limits in its variability, reflecting upon its previous exhibitions and eventual future presentations, giving place to a critical analysis, essential for its preservation.
\end{abstract}

Keyword: contemporary art conservation, variable media, behavior index, Joseph Kosuth, conceptual art 


\section{Arte conceptual}

Arte conceptual denomina um grupo de obras produzidas nas décadas de 60 e 70 que negam intencionalmente o valor atribuído ao objeto único em arte, sendo que a ideia ou 'conceito' é o aspeto mais importante da obra. A sua materialização apenas tem lugar no momento de exposição, cumpridas as instruções dadas pelo artista, e não exigindo a presença deste. 'Não-materiais' tais como a linguagem, e técnicas reprodutíveis como a fotografia ou outras sem cunho pessoal, são usados frequentemente (Stigter 2011).

No seu manifesto "Art After Philosophy" de 1969 (Kosuth 1991), Joseph Kosuth refere que o que está em causa na estética conceptual é a crítica da noção modernista de visualidade (ou opticalidade), aqui definida como uma esfera autónoma, separada da experiência estética. Além disso, está em causa o aspeto problemático do objeto artístico enquanto coisa única, bem como da novidade no modo de distribuição (o livro, o póster, o jornal) e a 'espacialidade' desse objeto (Foster 2004).

Em One and three plants (1965), obra aqui em análise, o artista expande o ready-made dividindo-o em três partes relacionais - planta, símbolo linguístico e reprodução fotográfica, apresentando a obra de arte enquanto "proposição apresentada no contexto da arte como comentário à arte" (Foster 2004).

Kosuth, líder do movimento, apresenta as suas obras como 'arte como ideia como ideia' (Fabre e Schlatter 2009; Kosuth 1991). One and three chairs (1965), uma cadeira, apresentada em forma, imagem e texto, marca o início das suas 'protoinvestigações', uma série de obras com o mesmo princípio mas diferentes objetos. Apesar de ser clara a irrelevância do objeto para a ideia da obra, foi o artista quem o escolheu, pelo que, na opinião de Stigter, o tipo e o material que os constitui acrescentam significado à 'investigação'. Assim, a atuação do conservador depende de questões como: de que forma interpretamos as instruções dadas pelo artista? (descritas no diagrama que acompanha a propriedade da obra); qual é a história da obra e da sua gestão curatorial? O que podemos aferir da site-specificity ${ }^{[1]}$ em relação com a intenção do artista? (Stigter 2011).

\section{Documentar arte conceptual}

A arte conceptual depende dum processo de materialização no contexto de uma exposição. Para tal, um somatório de escolhas determinantes e, por vezes, aparentemente insignificantes, são cruciais, apesar de raramente documentadas, já que o ímpeto documental surge frequentemene a partir do produto acabado. Este processo pode ser acompanhado pelo artista ou seus representantes, num diálogo fluido entre estes, curadores e conservadores (ou outros, dependendo das circunstâncias). O processo documental pode tornar rígida a fluidez destas relações adaptativas, podendo limitar materializações futuras deste tipo de obras. Portanto, sendo a documentação frequentemente o ponto de partida para as materializações, ela não se presta tradicionalmente ao registo de processos de natureza dinâmica, o que resulta numa tensão ambígua entre documento e manutenção de autenticidade. A questão é, então, qual o tipo de documentação que melhor reconhece as apreciações subjetivas dos decisores e garante a continuidade da obra de acordo com a sua natureza conceptual? A 'abordagem auto-etnográfica' (Stigter 2016) refere esta imputação subjetiva no âmbito da conservação que é raramente articulada nas práticas documentais habituais. Dada essa natureza subjetiva que se concretiza naquilo que o público vê objetivamente enquanto obra de arte, as decisões devem ser documentadas e fundamentadas num registo biográfico que constitui, no seu fluxo variável, a identidade da obra (van de Vall, Hölling, Scholte, Stigter 2011). Esta mesma ideia define uma nova perspetiva de conservação. No contacto com obras de natureza variável, o conservador é frequentemente confrontado com novas questões relativamente à sua materialidade e aparência que, não tendo sido colocadas a priori, acabam por ser determinantes. No caso particular da arte conceptual, estas questões são remetidas imediatamente ao processo de criação, já que o artista se demite de as materializar, imputando essa responsabilidade a terceiros. Temos, por exemplo: 1 - o artista como criador inicial; 2 - o diretor de museu que define o local; 3 - o conservador a reunir materiais e técnicas para a materialização da obra. Este aspeto colaborativo é frequentemente relegado para segundo plano, deixando por documentar as decisões que são tomadas por estes diferentes intervenientes (Stigter 2017). E, já que esta informação pessoal será ainda interpretada a posteriori, ela reforça a importância do registo permanente deste tipo de depoimentos, alertando para a importância de manter um pensamento crítico (Stigter 2015). Não obstante, não pretende o presente artigo aprofundar os aspetos de auto-etnografia ainda que sejam da maior relevância para a compreensão do fenómeno da tomada de decisões, mas sim analisar a eficácia duma ferramenta de gestão de arte conceptual (Stigter 2017).

Adicionalmente, o'modelo biográfico' ajuda a compreender de que forma a atribuição de significados varia ao longo da vida da obra de arte devido a mudanças no seu estado físico e na sua utilização, bem como de contextos social, cultural e histórico (Wharton 2015). A obra atravessa diferentes estados desde a sua criação e exposição inicial até à aquisição, documentação, armazenamento, exposição, empréstimo e intervenção de conservação e restauro, não necessariamente por esta ordem. Qualquer destes momentos representa uma oportunidade de contactar o artista (Wharton 2015). O artigo presente refere-se particularmente à fase de documentação, que apesar de ser frequentemente tida como o passo seguinte à aquisição, foi determinada como insuficiente, neste caso de estudo.

Importa referir que identificar a natureza autêntica ou verdadeira de uma obra para fins de conservação tem sido descartada pela literatura recente, por reconhecer que a 
autenticidade é percebida subjetivamente e tem desvios ao longo do tempo, com efeito quer no objeto de arte em si, quer nos valores culturais das pessoas que o experienciam (Wharton 2015). O termo 'intenção artística' como dogma representativo da ideia expressa pelo artista no momento da criação torna-se instável, uma vez que se pretende que a recordação duma situação passada permita a avaliação da situação presente (Wharton 2015). No entanto, o mesmo termo associado a uma obra de arte conceptual adquire um significado mais estável, já que o diagrama de instruções de montagem liga diretamente a exposição da obra às orientações determinadas aquando da formação da ideia pelo artista ('arte como ideia como ideia').

\section{—A ferramenta 'índice comportamental'}

A ferramenta 'índice comportamental' tem por base três modelos teóricos desenvolvidos recentemente com o intuito de gerir graus de variabilidade no âmbito da conservação de obras variáveis: 'media variáveis', 'análise biográfica' e 'análise auto-etnográfica', no contexto da Variable Media Initiative (Depocas, Ippolito e Jones 2003). Assim, estes modelos concentram-se na análise do 'comportamento' de determinada obra em vez das suas propriedades materiais ou técnicas, relacionando-a com os seus episódios biográficos (Depocas, Ippolito e Jones 2003). Três categorias então criadas serão relevantes para o 'índice comportamental' aplicado à arte conceptual: contido - quando uma obra reside objetivamente no seu material ou técnica original; instalado - quando a obra se realiza através da montagem de partes no momento da sua instalação; encenado - quando a obra é sempre feita de novo e necessita de uma ação em particular para ser realizada. As categorias comportamentais instalado e encenado permitem variações nas apresentações de determinada obra.

Não obstante a vantagem na atribuição destas categorias, o comportamento de uma obra pode mudar com e através do tempo, resultando em materializações e estratégias de preservação ora corretas, ora incorretas. A utilização do 'índice comportamental' permite posicionar num aparato visual as várias apresentações de determinada obra ao longo do tempo e acompanhar as suas mudanças de comportamento - da esquerda para a direita: contido, instalado, encenado, sinalizando uma dependência maior ou menor do suporte material.

\section{One and three plants, 1965}

Passei a ver a linguagem como um material legítimo a utilizar. (...) Por isso, a seguir utilizei cópias foto mecânicas de definições de dicionários numa série inteira de peças. Utilizei objectos comuns (...) e à esquerda do objecto estava uma fotografia em escala real deste e à direita do objecto estava uma cópia fotomecânica de uma definição do objecto extraída do dicionário. Tudo o que víamos quando olhávamos para o objecto tinha de ser o mesmo que víamos na fotografia, e por isso, sempre que o trabalho era exibido, a nova instalação precisava de uma nova fotografia. (...) Era muito interessante alterar a localização, o objecto, a fotografia, e continuar a ter o mesmo trabalho. Isto significava que podíamos ter uma obra artística que era a ideia de uma obra artística não sendo importantes os seus componentes formais. Senti que tinha encontrado uma forma de realizar arte sem os componentes formais se confundirem numa composição expressionista. A expressão estava na ideia, não na forma. As formas eram apenas um instrumento ao serviço da ideia2. (Fabre e Schlatter 2009)

One and three plants, 1965, (Inv. Nr. UID 102-321) é uma obra conceptual de Joseph Kosuth, parte do acervo do Museu Coleção Berardo (MCB). A história da obra pode ser dividida em três momentos para maior coerência da análise dos seus dados biográficos, já que representam um número crescente de documentação registada:

1 - antes de integrar a Coleção Berardo (CB);

2 - após integrar a $\mathrm{CB}$;

3 - após integrar o $\mathrm{MCB}^{[3]}$.

Partindo do momento de integração na $C B$, foi fornecido com a aquisição da obra o diagrama que especifica as instruções de montagem, e uma transparência com a definição de planta no dicionário de língua inglesa. A obra foi exposta no Sintra Museu de Arte Moderna - Colecção Berardo (SMAM-CB) ${ }^{[6]}$, antiga instituição de acolhimento da $C B$, tendo figurado em cinco exposições até 2007 (Coleção Berardo 2020), data em que integra o MCB. Presentemente, a obra está visível na exposição permanente do MCB e consiste especificamente em: uma planta euforbiácea4; duas impressões fotográficas a jato de tinta coladas sobre PVC e K-line.

\section{_Instruções de montagem de One and three plants}

A obra em análise consiste em: uma planta, uma fotografia dessa mesma planta, e uma impressão da definição de 'planta' no dicionário de língua inglesa, expostas in situ de acordo com as instruções do artista - [figura 1]. Estas instruções estão manuscritas no diagrama que acompanha a propriedade e que expressa ainda a escala da fotografia da planta (1:1), bem como a posição relativa de cada uma no espaço, mas carece de outras especificações. A literatura disponível existe maioritariamente à volta de One and three chairs, permitindo fazer pontes significativas entre ambas, já que são diferentes expoentes de um mesmo conceito. É partilhada a ideia de que o observador não se deva focar na autenticidade dos objetos materiais nem na ligação ao local, dado que a obra é sobre o esforço intelectual de conceptualizar e imaginar (Stigter 2011). Também se observa, em diferentes imagens de obras da mesma série, alterações na colocação dos objetos: alguns com a fotografia no chão, outros com a fotografia pendurada na parede. 


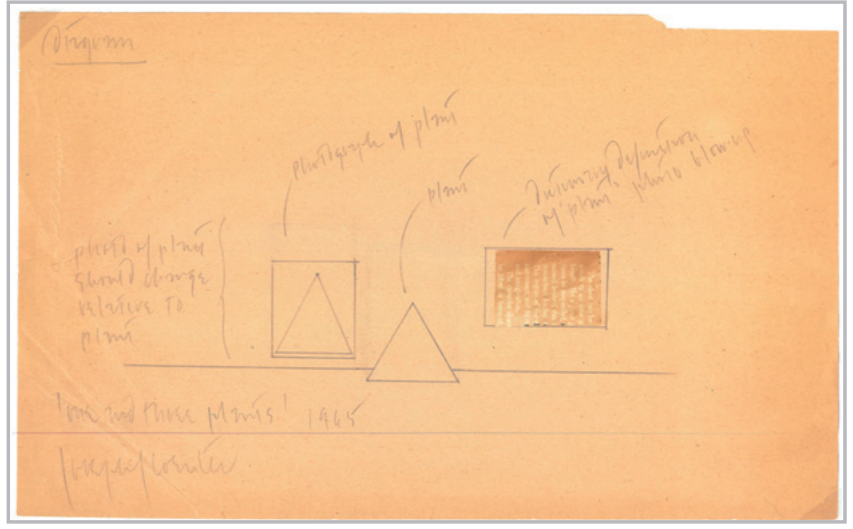

Figura 1.- Diagrama de montagem (Diagram) de One and three plants. Cortesia MCB.

Sempre que é necessário substituir a planta também se dá a substituição da imagem fotográfica. Tal como em todas as obras desta série, as características materiais não são determinadas porque não são relevantes para o conceito da obra, pelo que as imagens da planta e da definição podem ser reproduzidas em qualquer técnica ${ }^{[5]}$. Eventuais variações refletem escolhas dos diferentes intervenientes, conscientes ou determinadas pelas circunstâncias.

\section{-Site-specificity}

Apesar de o local de exposição não ser escolhido pelo artista (e poder ser um qualquer), surgiu a dúvida se a fotografia da planta teria de ser registada no local em que a obra é exposta, após análise da literatura e comparação entre montagens de One and three plants e de outras obras da mesma série, já que este facto não foi respeitado nas diferentes materializações. Outras 'proto-investigações' são encontradas quer com uma nova fotografia feita in situ, quer sem relação com o local onde vai ser exposta a obra. Apesar de não especificado no diagrama, os escritos do artista bem como os catálogos autorizados mostram as 'proto-investigações' como site-specific, com uma fotografia feita no local de exposição da obra. Finalmente, através de esclarecimento direto com o artista, apurou-se que este aspeto é mandatório:

"The new cactus should then be situated in the exact location where it will be in the final installation as the floor will be visible in the photograph of the plant. The lighting situation must also be exactly replicated."(Smith 2020)

Apesar das diferentes materializações não datarem todas do mesmo tempo, o artista considera todas como sendo de 1965, ano da criação do conceito. Por tal, o argumento que teria sustento na primeira materialização de determinada obra desta série como sendo o modelo para subsequentes montagens, cede lugar ao da substituição da fotografia por uma nova sempre que a obra é reinstalada noutro local. É, também, aqui, que a ferramenta índice comportamental pode traduzir de que modo a renovação da obra não põe em causa as propriedades que a definem, verificando assim uma unidade ética na sua preservação ao longo do tempo e em diferentes contextos (Stigter 2011).

\section{—Tomada de decisões}

As decisões a tomar em caso de nova montagem devem refletir a importância de combinar evidência material com investigação histórica. Isto é crucial no caso da arte conceptual em que os intervenientes estarão efetivamente a (co)recrear a obra, ou mesmo a incorrer numa performance que acaba por significar 'fazer' a obra (Stigter 2011). Em One and three plants, esta questão é-nos imposta pela natureza do objeto 'planta' que, pela sua existência perecível, nos força a tomar decisões acerca dos restantes materiais que a acompanham. É aqui que importa equacionar quais os aspetos que fazem parte da obra e quais os que não fazem. Havendo poucos registos fotográficos das mostras até 2007, podemos especular acerca da espécie de planta apresentada e se esta teria acompanhado a venda da obra. De acordo com o depoimento da gestora da coleção à data, Isabel Alves, a própria adquiriu um cato para ser fotografado e exposto. Ao ler-se a definição de planta, pode aferir-se que a questão levantada quanto à espécie a utilizar seria pertinente. Em 2014, o registrar António Mendes contactou a diretora do SMAM-CB, Maria Nobre Franco, que retorquiu que o curador Fernando Capelo ${ }^{[7]}$ mencionava sempre que tinha 'comprado um cato do Kosuth'. O diretor do MCB, quando questionado acerca da espécie a escolher, notava, porém, que:

'A reposta à questão é muito simples: eufórbia ou cato é irrelevante, o que é fundamental é ser o mais próximo possível da fotografia original. A partir daí fazemos uma nova fotografia da planta de forma a que a imagem seja a da planta real que é mostrada na obra. O Kosuth nunca se preocupou se era uma coisa ou outra. O problema é outro, e a definição é mais genérica do que isso.' (Lapa 2014)

Será possível especular que o recurso a um cato ou similar se devesse às suas características de resistência e baixa manutenção. Na pesquisa em catálogos on-line, sustentase esta tese, uma vez que são identificadas outras espécies, nomeadamente pequenas palmeiras e outras plantas de interior, integrando outras obras da mesma série [figura 2]. Contactada a galeria Sprüth Magers, o diretor responde às questões da seguinte forma:

(...) the cactus can definitely be replaced with another plant. The plant will then need to be photographed in the very room in which the work is going to be shown and this print will replace the print with the cactus. Picking a cactus was a conscious yet arbitrary decision. (Gegner 2020)

Em conversa com Lapa em 2020 (Lapa 2020), acerca da sua referência a uma planta "o mais próximo possível da fotografia original", e do que se deve considerar como relevante (ou irrelevante) na série de 'definições' de Kosuth, Lapa descreve que não é desejável utilizar uma planta com 
atributos estéticos particulares e que a proposição da obra é suportada de forma mais eficaz se o mesmo tipo de planta for utilizado.

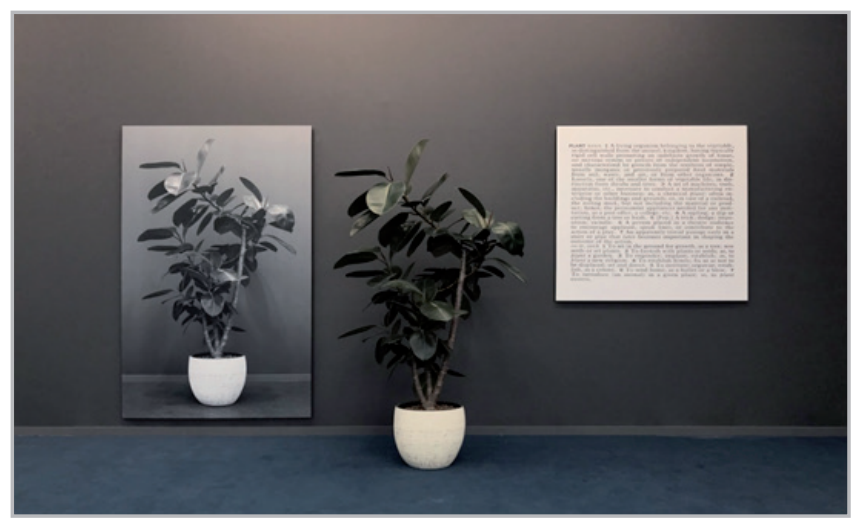

Figura 2.- Formulação de outra versão de One and three plants para a Galeria Castelli na feira de arte Frieze em 2018. A planta foi selecionada pelo artista (Smith 2020). ๑ Joseph Kosuth.

A imagem de referência que acompanhou a aquisição da obra foi publicada no livro Joseph Kosuth 1965 \& 1967 (Renée Ziegler 1992), no âmbito duma exposição em 1992 na Galerie Renée Ziegler em Zurique ${ }^{[8]}$ - [figura 3]. Porém, após contacto com o estúdio do artista com o intuito de obter registos relativos à sua primeira apresentação pública, conclui-se que essa imagem corresponde a uma exposição em 1965, apesar de se desconhecer o contexto (Smith 2020).

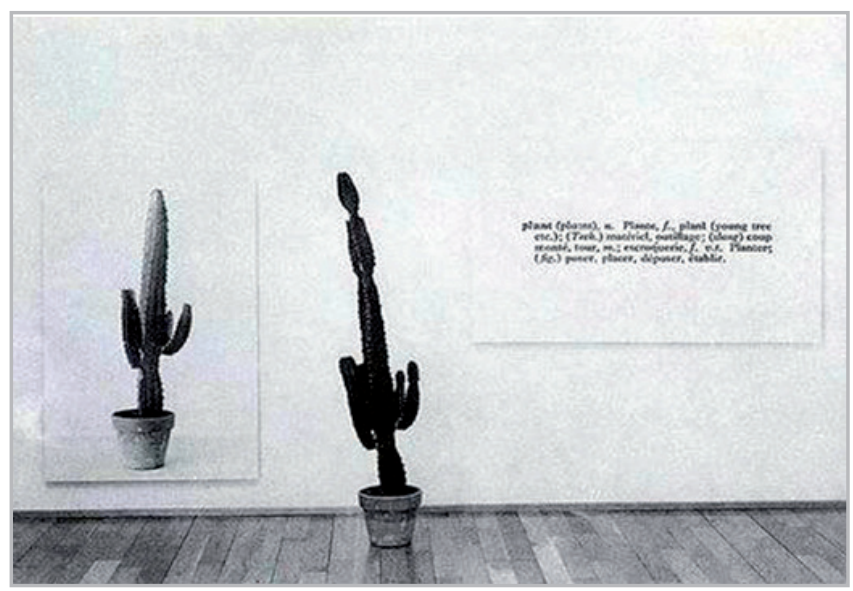

Figura 3.- Registo mais antigo da materialização de One and three plants ${ }^{[9]}$, data e localização desconhecidas (Smith 2020). ( Joseph Kosuth

Além da técnica de reprodução fotográfica e impressão da definição não serem explicitadas pelo artista, também as dimensões de cada um desses suportes são omissas. Ao longo dos episódios biográficos no $M C B$, foi utilizada uma dimensão de referência com base nas versões de materializações anteriores, porém, não existe qualquer menção a uma hipotética dimensão original da primeira materialização. A escolha da planta assenta, assim, sobre duas suposições que têm sustento no histórico da obra.
A primeira, relativamente à espécie - cato, eufórbia, ou semelhante -, e a segunda relativamente à sua dimensão, já que essa não poderá ultrapassar a dimensão do painel fotográfico. Por fim, a própria escolha da fotografia a preto e branco - determinada pelas limitações tecnológicas à data continua a remeter a obra para um determinado momento histórico, apesar da técnica escolhida ser habitualmente uma impressão a jato de tinta (um processo de impressão fotográfica a cores). Ainda que a técnica escolhida seja contemporânea e não remeta para esse momento de criação da obra, serve o argumento de que forçar essa relação seria novamente distanciar o processo de montagem da obra daquilo que é relevante reter e que se opõe a questões técnicas e materiais.

\section{Registo biográfico}

Antes de integrar a CB, o histórico da obra era desconhecido, não sendo possível rastrear a sua primeira materialização. Após contacto com o estúdio do artista, confirma-se que a obra terá sido materializada em 1992 em Zurique e em 1965 em versão francesa, sem possibilidade de obtenção de outros dados relativos a esta montagem (Smith 2020).

Quando analisado o sumário biográfico da obra, atestamos:

1 - Antes de 2014, a obra estava mais dependente das suas componentes 'originais', mas a necessidade de substituição de uma planta moribunda forçou a substituição do organismo vivo e, subsequentemente, da sua imagem fotográfica.

Assim, até 2014, houve uma procura por um 'cato' semelhante na tentativa de evitar transformar a obra numa outra coisa, e dando, assim, alguma contingência às suas componentes materiais. Com isto, a obra sofreu um ligeiro desvio no sentido do comportamento contido, apesar da substituição da planta, uma vez que se almejou a similitude a uma planta 'original'.

2 - Depois de 2014, considerando mais profundamente a verdadeira natureza da obra, um ligeiro desvio comportamental no sentido encenado (relativo à subjetividade inerente à escolha da 'planta') teve lugar, mas ainda apenas em teoria.

3 - Em 2020, questionados a galeria e o artista acerca da possibilidade de alteração da espécie de planta, confirmase que a utilização de cato ou eufórbia não é mandatória, apesar de estar sujeita a aprovação do artista.

4 - Finda a investigação espoletada pelo artigo presente, confirma-se a necessidade de relacionar a fotografia da planta com a sua localização na sala onde a obra será exposta.

5 - No futuro, havendo a decisão curatorial de substituir a planta por outra espécie nunca utilizada na sua biografia, estar-se-á a provocar um desvio ontológico? Ou bastará a 
definição de planta para estabelecer as fronteiras duma substituição ontologicamente aceitável?

Será claro que um elemento tem sido mantido desde o momento de aquisição - a definição de planta. Este comportamento contido deve-se, no entanto, a conveniência e economia de meios, dado que é desnecessário reimprimir a definição por ser sempre a mesma. Uma aproximação da última questão leva a indagar se a obra - que na sua natureza integralmenteconceptual tem um comportamento instalado - pode existir legitimamente com um comportamento contido. Estar-se-á a promover uma apresentação incorreta da obra se a planta mudar radicalmente, ainda que englobada pela definição de planta? A indagação que surge do ímpeto documental do conservador-restaurador pode, no caso, desviar a proposição que a obra representa, atribuindo excessiva relevância à espécie de planta, o que resulta numa distração da verdadeira natureza da obra enquanto ideia. Portanto, pretende o presente demonstrar concordância com a posição de Lapa ao cingir a planta a uma 'semelhante', não por ela ser importante enquanto tal, mas precisamente por não o ser. Esta ideia reforça-se pela necessidade de autorização do artista se for pretendido alterar a espécie de planta, enfatizando a dependência deste que, se for mantida a aproximação à planta 'habitual' se torna desnecessária.

Pode ainda dar-se o caso de, no futuro, ser essencial a substituição da espécie de planta-pondo a hipótese extrema de extinção, dada a sua natureza orgânica. No caso, crê-se, finda esta explanação, que se tenha conseguido balizar os limites do aceitável na substituição deste elemento. No caso de necessidade de reimpressão da 'definição', pode ser necessário substituí-la por mostrar traços visíveis de deterioração, e pode ainda dar-se o caso de, no momento da sua substituição, a técnica previamente utilizada já estar obsoleta, obrigando a uma renovação dos meios técnicos. Isto significaria um desvio para o lado encenado da ferramenta de monitorização comportamental.

\section{Aplicação da ferramenta 'índice comportamental'}

Ohistórico da obra demonstra um desvio do comportamento instalado (1965) na sua primeira materialização, a contido na materialização sem data ilustrada na [figura 3] - onde não existe correlação entre o chão do local onde está exposta e o chão representado na fotografia, deduzindo-se que a fotografia foi recuperada duma montagem prévia -, a instalado quando foi adquirido pela CB.

Posteriormente à incorporação no $\mathrm{MCB}$, é possível situar a obra nas seguintes categorias comportamentais, a partir dos diversos registos biográficos, todos ocorridos na sala de exposições do MCB:

1. Contido: Quando foi exposta no MCB 2008 (o chão da fotografia não coincide com o chão do local, perdeu-se a site-specificity) - [figura 4a]
2. Contido: Quando a obra não respeitou a posição relativa dos elementos em 2013 [figura 4b]

3. Instalado: Quando foi mudada a planta em 2014 - [figura 4c];

4. Contido: Antes da substituição tardia da planta em 2016 (uma planta morta não serve a intenção do artista) - [figura 4d]

\section{Instalado: Quando foi mudada a planta em 2016}

6. Encenado: Quando foi montada em 2019 (a iluminação da obra apresenta uma tonalidade vermelha que não corresponde às instruções obtidas do Estúdio do Artista em 2020, apesar dos elementos serem os mesmo de 2016) [figura 4e]

7. Encenado: Quando foi mudada a planta em 2020 (a fotografia da planta não respeitou a escala 1:1) - [figura 4f]

O 'índice comportamental' localiza no tempo as diferentes montagens de One and three plants e a distância a que estas estiveram do eixo definido como o que mais se aproxima da natureza autêntica da obra. Partindo da informação agora adquirida, conclui-se que o comportamento instalado seria o que mais descreve uma correta materialização da obra. No entanto, o ato de registar a fotografia no espaço de exposição, bem como a escolha duma planta (sempre diferente, ainda que semelhante), e ainda a escolha da técnica de impressão da fotografia e dimensões, promovem um ligeiro desvio no sentido do comportamento encenado, já que requer apreciações subjetivas e ações únicas para efetivar a materialização - [figura 5].

Importa, então, analisar os eventuais desvios do comportamento de referência, nos sentidos contido e encenado, justificando as incorreções decorridas. Situase a obra num comportamento contido em duas das suas exposições porque as materializações utilizadas omitiram, por um lado, a ligação site-specific - chão da fotografia e chão da sala de exposição não coincidem 10 -, e por outro, o estado orgânico da planta - deve estar viva e saudável, sob pena de prejudicar a apreciação estética e conceptual da obra. A última decorre de apreciações do senso comum, mas que acabaram por ser confirmadas pelo estúdio do artista: "Last of all I am sending an image that I believe was on Instagram of the Berardo cactus in poor condition." (Smith 2020)

Apesar dos suportes materiais apenas servirem o propósito de revelar a ideia da proposição feita pelo artista, importa referir quais as condições que esses materiais devem observar, já que a sua substituição será frequente. A fotografia é, além duma imagem da planta, um objeto com determinadas características que ultrapassam a função da representação. Estas características estão relacionadas com a data de criação da obra e as escolhas feitas então: o facto de ser a preto e branco, provavelmente uma gelatina sal de prata na sua primeira materialização, como outras obras da 

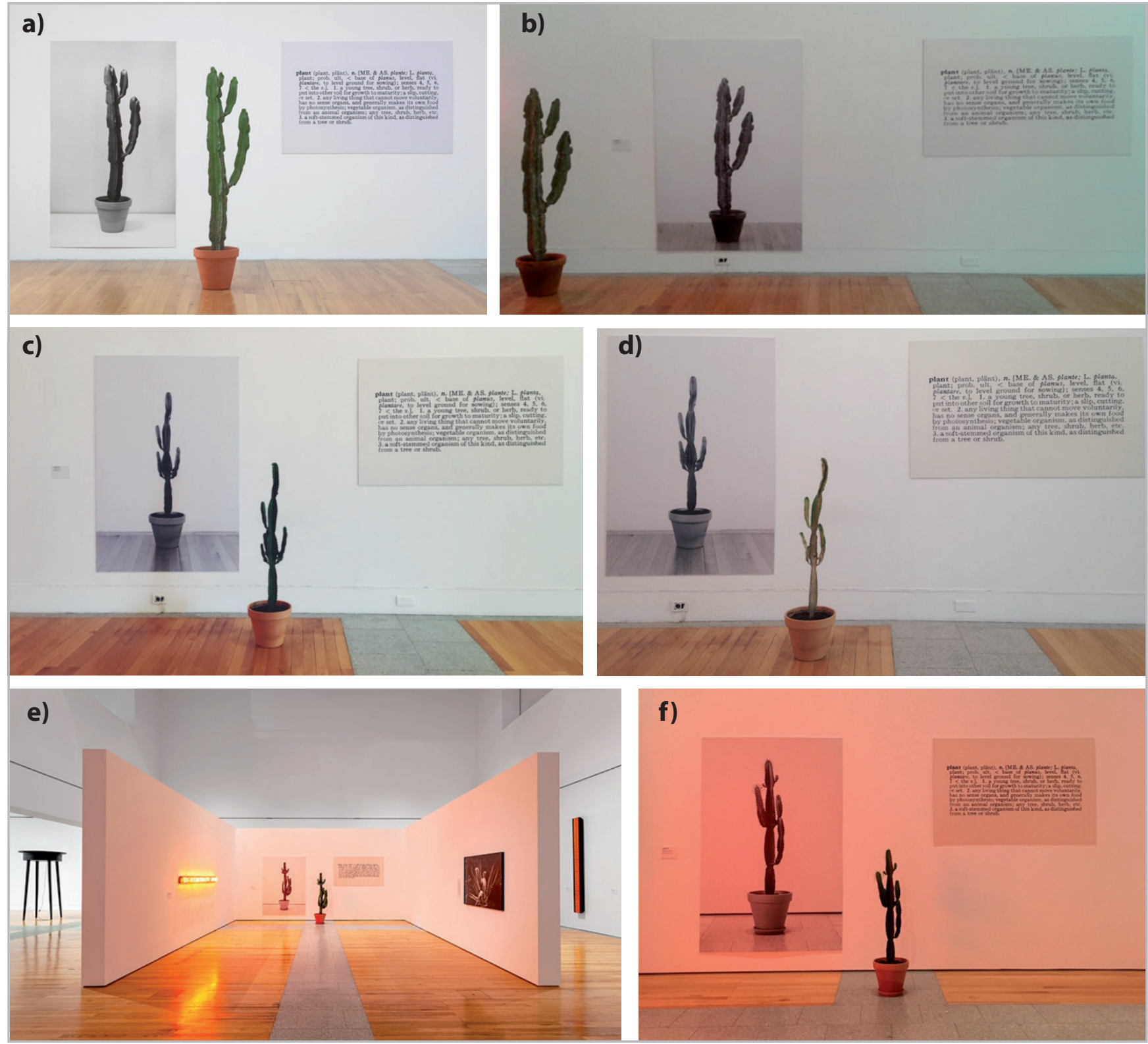

Figura 4.- 4a) Imagem de One and three plants montada em 2008: o chão visível na impressão fotográfica não é o da sala de exposição. Crédito: David Rato. Cortesia MCB. 4b) Imagem retirada da internet, relativa à obra exposta em 2013 (Laborativo 2014). Cortesia MCB. 4c) Imagem de One and three plants com alteração da planta e sua fotografia, 2014. Cortesia MCB. 4d) Imagem de One and three plants com planta moribunda. Cortesia MCB. 4e) Sala de exposição com One and three plants iluminada pela obra Self-described and selfdefined de Joseph Kosuth, na exposição Constelações Il: uma coreografia de gestos mínimos, 10/10/2019 - 05/10/2020, no MCB. Crédito: David Rato. Cortesia MCB. 4f) Imagem de One and three plants em que a fotografia da planta não respeitou a escala 1:1. Cortesia MCB

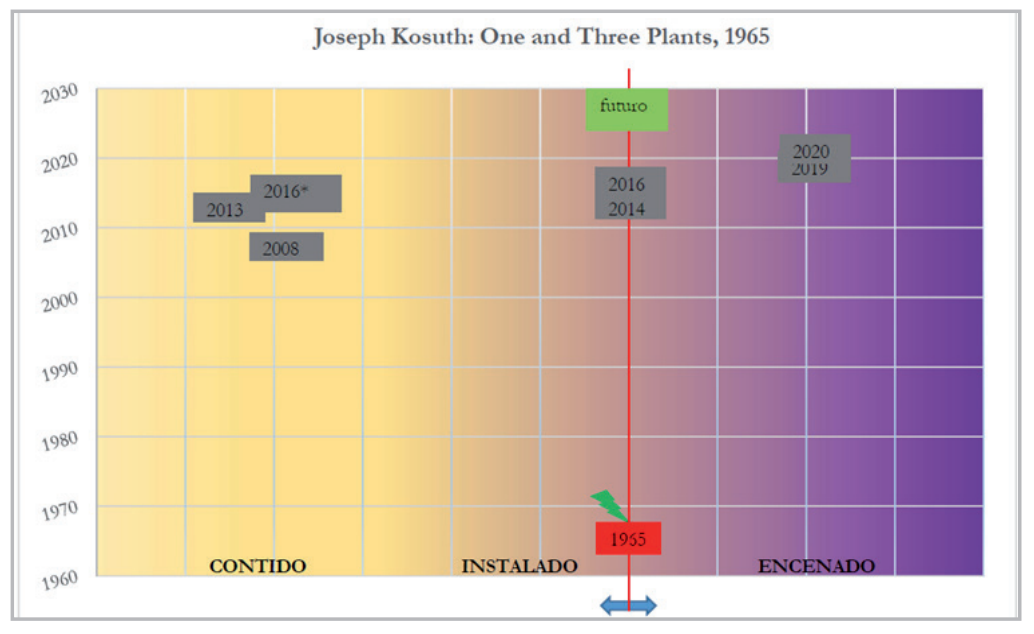

Figura 5.- índice comportamental para a obra One and three plants, 1965 de Joseph Kosuth. O eixo vertical vermelho indica o comportamento mais fiel à natureza da obra: instalado, com um ligeiro desvio para encenado. As datas das diferentes montagens situam-se mais à esquerda ou mais à direita, correspondendo a desvios do eixo considerado normal. 2016* - Momento em que a obra foi exposta com uma planta moribunda. 
mesma série, técnica comumente utilizada para grandes formatos nesta época (Stigter 2011). A escolha de um registo fotográfico digital e subsequente impressão a jato de tinta não implica as mesmas limitações de tamanho da prova que uma materialização analógica poria em 1965. Devese, portanto, ter em conta a dimensão limite das provas a gelatina sal de prata na data de criação da obra, como uma dimensão aproximada para a escolha da nossa planta e respetiva fotografia. A literatura sugere que, à data de 1965, seria impossível gerar uma fotografia (gelatina sal de prata) maior do que 120 x $120 \mathrm{~cm}$ (Stigter 2011). Apesar das materializações terem ultrapassado esta medida (impressão atual: $147 \times 100 \mathrm{~cm}$ ), conclui-se que será de almejar manter o elo ao tempo de criação, ainda que através de dimensões aproximadas.

A forma de fixação da fotografia e da definição na parede também carecem de especificação, no entanto, observando imagens de outras montagens [figuras 4a-f], conclui-se que se manteve a forma de fixação: fotografia colada sobre PVC ou K-line, sem moldura, fixa de forma invisível na parede. A posição relativa dos elementos, apesar de não detalhada no diagrama, respondeu à mesma linha de orientações a partir de imagens de montagens anteriores.

\section{Conclusão}

A análise das materializações de One and three plants levanta questões fundamentais sobre a natureza da obra e sobre a sua gestão no âmbito museológico. Apesar dos aspetos não determinarem a natureza da obra, os conhecimentos do conservador-restaurador e consequentes indagações acerca das particularidades técnicas e materiais, acabam por ser fulcrais na definição de corretas materializações da obra no futuro. A natureza subjetiva do processo de decisão deve ser documentada com clareza, recorrendo às estratégias descritasparaquesepossa prevenirumaindagaçãoqueesteja demasiado ligada aos constrangimentos e possibilidades técnicas do tempo de cada nova materialização(Stigter 2011). O facto da intenção do artista não permitir definir o que é a obra (Wharton 2015), apesar de se aproximar dela no caso da arte concetual, reforça a importância duma ferramenta como o 'índice comportamental', que permite o registo e a revisão das existências da obra em determinado momento da sua história. Permite, assim, contrapor o resultado desse somatório com o contexto de intenção artística e definir se os seus comportamentos estão a distanciar-se da sua natureza original e/ou da sua verdadeira natureza. Resulta, portanto, numa revelação esquemática do impacto da prática museológica e seus intervenientes na conservação, instalação e encenação de determinada obra. O papel do conservador enquanto mediador e corpo documental (Marçal 2017) garantirá, de forma mais consolidada, uma apresentação da obra que seja escolhida de forma cuidadosa e consciente, respeitando a sua massa crítica, no sentido de garantir um conjunto de escolhas que visam a manutenção dos atributos que demonstram a verdadeira natureza da obra (Gordon 2014).
Idealmente, esta ferramenta de gestão de obras de arte conceptual seria integrada digitalmente nas bases de dados de gestão de coleções, para obras de características variáveis. Permitiria, assim, fazer uma súmula biográfica dos episódios relevantes das exposições de determinada obra, auxiliando a tomada de decisões aquando de futuras exposições e uniformizar a linguagem analítica utilizada para diferentes obras.

\section{Notas:}

[1] Uma obra diz-se site-specific quando o local onde será exposta é refletido na aparência da obra finda a sua montagem.

[2] [Esta entrevista foi transmitida na WBAl-FM, a 7 de Abril de 1970. Foi publicada posteriormente como "Joseph Kosuth: Artas Idea as Idea" in Jeanne Siegel, Artwords: Discourse or the 60s and 70s, UMI Research Press, Ann Arbor, Michigan, 1985, pp. 221-231.] (Fabre e Schlatter 2009)

[3] O Museu Coleção Berardo, fundado em 2006, surge da conjugação de recursos públicos com a coleção particular do Comendador Berardo (aqui denominada de Coleção Berardo), a fim de, partindo dum conjunto de obras desta, se construir um Museu sito no Centro Cultural de Belém, em Lisboa.

[4] A terminologia correta para a planta que o MCB pensava ser um cato, de acordo com a Enga. Isabel Moura, do Jardim Botânico Tropical de Belém, a quem foi solicitada assistência na substituição da planta por uma similar (2014).

[5] O diagrama refere o termo Photostat, nome comercial de uma máquina fotocopiadora usada na indústria gráfica, principalmente na primeira metade do século XX. A imagem era impressa diretamente em papel fotossensível, a partir dum primeiro Photostat em negativo que é usado para fazer novos Photostats para imagens positivas (Stigter 2011). Apesar dessa referência, impressões analógicas em gelatina sal de prata bem como a jato de tinta têm sido utilizadas.

[6] Museu que albergava a Coleção Berardo, entre 1997 e 2007.

[7] Curador responsável por parte da seleção das obras adquiridas para a Coleção Berardo.

[8] A Galeria foi inquirida a fim de obter fotografias da exposição em que se pudesse observar a obra em questão, sem sucesso.

[9] Informação e imagem fornecidas pelo estúdio do artista em 2021.

[10] É possível que se tenha querido reutilizar uma imagem registada noutro local, já que a planta continuava a ser a mesma.

[11] Imagens relativas a materializações de outras obras da mesma série sugerem fixação da imagem e da definição com pionés e pregos sobre o papel diretamente na parede, ou com escápulas. 


\section{Referências}

COLEÇÃO BERARDO, One and three plants, Joseph Kosuth, https:// www.berardocollection.com/?sid $=50004 \&$ CID $=102 \&$ work $=321 \&$ la ng=pt, [28.01.2021].

DEPOCAS, A., J. IPPOLITO, and C. JONES, eds. (2003). Permanence through change: The Variable Media Approach / L'Approche des Médias Variables: La permanence par le changement. New York and Montreal: Guggenheim Museum and Daniel Langlois Foundation for Art, Science, and Technology

FABRE, E. e SCHLATTER, C. (2009). Algumas obras a ler, Lisboa, Museu Coleção Berardo.

FOSTER, H. (2004). Art since 1900: modernism, antimodernism, postmodernism. London, Thames \& Hudson, (pp. 603-604, 607, 663).

GALERIE RENÉE ZIEGLER (1992). Joseph Kosuth, Protoinvestigations 1965 \& The first investigations 1967, Zurique

GEGNER. A. Correspondência eletrónica, Galeria Sprüth Magers [2.06.2020].

GORDON, R. (2014). "Identifying and pursuing authenticity in contemporary art.", Gordon, R., Hermens, E. and Lennard, F. (eds.) Authenticity and Replication: The 'Real Thing' in Art and Conservation. Archetype Publications: London, UK.

KOSUTH, J. (1991). Art after Philosophy and After: Collected Writings, 1966-1990, Gabriele Guercio (Ed.), Cambridge: MIT Press, https:// monoskop.org/images/4/46/Kosuth_Joseph_1969 1991 Art After Philosophy.pdf.

LABORATIVO (2014). Especial Viagem: O Museu Berardo é pura surpresa!. http://laborativo.blogspot.com/ [consulta: 22/09/2020].

LAPA, P. Correspondência eletrónica, Museu Coleção Berardo [consulta: 18/02/2014].

LAPA, P. Conserva telefónica, Museu Coleção Berardo [consulta: 15/05/2020].

MARÇAL, H. (2017). "Conservation in an era of participation". Journal of the Institute of Conservation, 40(2): 97-104. https://doi. org/10.1080/19455224.2017.1319872.

SMITH, C. Correspondência eletrónica, Joseph Kosuth Studio, Nova lorque [consulta: 11/11/2020].

STIGTER, S. (2011). “How material is conceptual art? From certificate to materialization: installation practices of Joseph Kosuth's 'Glass (one and three)!'” Em T. Scholte, \& G. Wharton (Eds.), Inside installations: theory and practice in the care of complex artworks: 6980. Amsterdam University Press.

STIGTER, S. (2015). “Co-Producing Conceptual Art: A Conservator's Testimony. RHA 04: Performing Documentation in the Conservation of Contemporary Art, (Eds.). Matos, L.A., Macedo, R., Heydenreich, G.
Instituto de História da Arte, Universidade Nova de Lisboa, Lisboa. STIGTER, S. (2016). "Autoethnography as a new approach in conservation", Studies in Conservation: IIC 2016 LA Congress: Saving the Now 61(S2): 227-32. http://dx.doi.org/10.1080/003936 30.2016.1183104.

STIGTER, S. (2017). "A behaviour index for complex artworks: A conceptual tool for contemporary art conservation." ICOM-CC 18th Triennial Conference Preprints, Copenhagen, 4-8 September 2017, ed. J. Bridgland, art. 0910. Paris, International Council of Museums. https://dare.uva.nl/search?identifier=210b66af-e4f8-40bb-a3adfff65864bb57

VAN DE VALL, R., HÖLLING, H., SCHOLTE, T., \& STIGTER, S. (2011). "Reflections on a biographical approach to contemporary art conservation". J. Bridgland (Ed.), ICOM-CC: 16th Triennial Conference, Lisbon, 19-23 September 2011: preprints [cd-rom] Critério. https:// dare.uva.nl/search?identifier $=$ d2340 d58-6edb-49e9-baa8c87ee11804e9.

WHARTON, G. (2015). "Artist intention and the conservation of contemporary art". Hamilton, E., Dodson, K. (Ed.) Objects Specialty Group Postprints, Volume 22: 1-12. Washington, DC, The American Institute for Conservation of Historic \& Artistic Works. http:// resources.culturalheritage.org/osg-postprints/wp-content/ uploads/sites/8/2015/05/osg022-01.pdf.

\section{Autor/es}

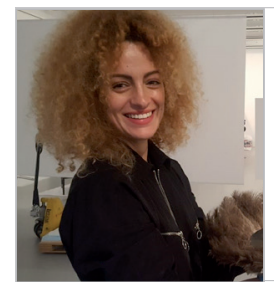

\author{
Francisca Sousa \\ francisca.sousa@museuberardo.pt \\ Museu Berardo
}

Mestre em Conservação e Restauro pela Faculdade de Ciências e Tecnologia da Universidade Nova de Lisboa, estagiou no Museu do Chiado - Museu Nacional de Arte Contemporânea (2007), tendo como especialização a Conservação Preventiva e a Conservação e Restauro de arte contemporânea - vertente materiais poliméricos. Obteve o grau de mestre em Gestão de Coleções (2019). Exerceu funções de conservadora-restauradora na Ellipse Foundation Contemporary Art Collection entre 2007 e 2011. É também membro do CEMES - Centro de Estudos Multidisciplinares Ernesto de Sousa e desde 2011 trabalha como registrar no Museu Coleção Berardo. As suas mais recentes pesquisas e formação incidem sobre ética em conservação e conservação de novos media.

https://doi.org/10.37558/gec.v19i.988 